\title{
Solvothermal Synthesis of $\alpha-\mathrm{Al}_{2} \mathrm{O}_{3}$ from Boehmite with Seeding Technique
}

\author{
Hye Youn Jo****, Min-Gyeong Park*, Seung-Ho Lee*, Dae Sung Kim*, \\ Young Kwan Lee**, and Hyung Mi Lim**, \\ *Eco-composite Materials Team, Korea Institute of Ceramic Engineering \& Technology (KICET), \\ Jinju 660-031, Korea \\ ${ }^{* *}$ School of chemical Engineering, Sungkyunkwan University, Suwon 440-746, Korea \\ (Received June 25, 2015; Revised July 14, 2015; Accepted July 14, 2015)
}

\begin{abstract}
a- $\mathrm{Al}_{2} \mathrm{O}_{3}$ was synthesized by solvothermal synthesis using $\mathrm{a}-\mathrm{Al}_{2} \mathrm{O}_{3}$ seed, precursor of fine boehmite $(\mathrm{Al}(\mathrm{OOH}))$ or gibbsite $\left(\mathrm{Al}(\mathrm{OH})_{3}\right)$, and 1, 4-butanediol solvent. The seed content and precursor type were selected as variables in order to synthesize $\alpha-\mathrm{Al}_{2} \mathrm{O}_{3}$. The formation time of $\alpha-\mathrm{Al}_{2} \mathrm{O}_{3}$ was reduced and the size of the particles was decreased with addition of the seed. When the seed content was increased, the size of the synthesized $\alpha-\mathrm{Al}_{2} \mathrm{O}_{3}$ was reduced. Morphologies of the as-synthesized $\alpha-\mathrm{Al}_{2} \mathrm{O}_{3}$ with $\alpha-\mathrm{Al}_{2} \mathrm{O}_{3}$ seed were polyhedron-shaped, while the shape was plate-like or polyhedral without the seed, depending on the additives or the average particle size of the boehmite precursor. The aggregation of as-synthesized $\alpha-\mathrm{Al}_{2} \mathrm{O}_{3}$ from boehmite was smaller than that from gibbsite. As-synthesized $\alpha-\mathrm{Al}_{2} \mathrm{O}_{3}$, with $140 \mathrm{~nm}$ size, was obtained by using the seed and boehmite precursor.
\end{abstract}

Key words : Solvothermal synthesis, $\mathrm{a}_{-} \mathrm{Al}_{2} \mathrm{O}_{3}$, Seeding technique, Crystal growth

\section{Introduction}

A lumina has excellent properties in both chemical and mechanical aspects, such as high chemical stability, strength, and hardness. It is a typical ceramic material most frequently applied as catalysts, abrasives, substrates, abrasion-resistant materials, etc. ${ }^{1,2)}$ And its high thermal conductivity compared to organic materials provides an additional application as an additive to polymer-based electronic components. ${ }^{3)}$

There are numerous ways of synthesizing alumina; sol-gel method, ${ }^{4)}$ gas-phase reaction, ${ }^{5)}$ calcination, ${ }^{6-8)}$ hydrothermal synthesis, ${ }^{9}$ solvothermal synthesis, ${ }^{10-13)}$ etc. Sol-gel method involves in reaction in a liquid phase with Al-containing precursor. Gas-phase reaction produces particles from gasphase precursor introduced in a tubular reactor, followed by either thermal decomposition or chemical reaction. Calcination uses high-temperature heat treatment of alumina hydride that decomposes into alumina. For example, boehmite or gibbsite produces $\alpha-\mathrm{Al}_{2} \mathrm{O}_{3}$ under heat treatment at $1200 \sim 1300^{\circ} \mathrm{C}$.

Solvothermal synthesis employs organic solvents such as glycol or diol at relatively low temperatures $\left(<300^{\circ} \mathrm{C}\right)$. The process can provide several advantages in achieving high-quality product; high purity, mono-distribution in size, and manipulation of particle morphology by using additives (for example, shapes of cube, sphere, diamond, triangular cone, etc.)

${ }^{\dagger}$ Corresponding author : Hyung Mi Lim

E-mail : lim@kiect.re.kr

Tel : +82-55-792-2450 Fax : +82-55-792-2456
Seeding is widely adopted in $\mathrm{a}-\mathrm{Al}_{2} \mathrm{O}_{3}$ synthesis to enhance reaction rate and to have a certain phase selectively. The method provides a decrease in overall surface energy for overcoming the nucleation barriers, and thus increases in nucleation frequency, and consequently, reduces synthesized particle size. It is known that the seeding effects are generally notable with the addition of $\alpha-\mathrm{Al}_{2} \mathrm{O}_{3}, \alpha-\mathrm{Fe}_{2} \mathrm{O}_{3}$ whose lattice parameters are similar to those of $\alpha-\mathrm{Al}_{2} \mathrm{O}_{3}$, and $\mathrm{AlF}_{3}{ }^{12-15)}$

Preventing or minimizing the agglomeration phenomenon that frequently occurs at high temperatures has been a hot issue to be resolved for the formation of $\alpha-\mathrm{Al}_{2} \mathrm{O}_{3}$. A series of studies thus has been focused on reducing the reaction temperature. ${ }^{15-18)}$ One previous study reported, by using $\alpha-\mathrm{Al}_{2} \mathrm{O}_{3}$ seeds, a formation of nano-sized $\alpha-\mathrm{Al}_{2} \mathrm{O}_{3}$ particles via annealing of boehmite precursor at temperatures below $1150^{\circ} \mathrm{C}$. Another study emphasized that, using precursors such as $\mathrm{AlP}, \mathrm{AlCl}_{3}, \mathrm{Al}(\mathrm{NO})_{3}$ and $\mathrm{AlOOH}$ with $\mathrm{AlF}_{3}$ seeds can produce micron-sized $\alpha-\mathrm{Al}_{2} \mathrm{O}_{3}$ via sol-gel route at temperatures as low as $750^{\circ} \mathrm{C}$. ${ }^{15)}$

Solvothermal technique also provided $\alpha-\mathrm{Al}_{2} \mathrm{O}_{3}$ particles close to nano-size from gibbsite precursor with $\alpha-\mathrm{Al}_{2} \mathrm{O}_{3}$ seeds. ${ }^{11,12)}$ Previous studies on solvothermal method, however, revealed few details on the effect of precursor, although the feasibility of fine $\alpha$-alumina formation had been clearly demonstrated. One study claimed that solvothermal synthesis of $\alpha$-alumina from boehmite precursor was affected by the particle size of precursor on the growth rate of particles and their morphology development. ${ }^{19)}$

This study thus involves in solvothermal synthesis in respect to different precursors, boehmite and gibbsite, and 
to seeding effects. We analyzed the sizes of synthesized alumina, their morphologies, and the agglomeration in terms of seed content, precursor type size and its dispersion.

\section{Experimental Procedure}

\subsection{Raw materials}

Boehmite (Dispal T25N4, Sasol) and gibbsite (KH-101, $\mathrm{KC}$ Co., Korea) are used as the starting powders. We dispersed boehmite in methanol by ultrasonication for $5 \mathrm{~min}$, while gibbsite by ultrasonication or ball milling to evaluate the effect of dispersion on $\alpha-\mathrm{Al}_{2} \mathrm{O}_{3}$ formation. We ball milled gibbsite powder in ethanol solvent at adjusted $\mathrm{pH}$ of 3 at $200 \mathrm{rpm}$ for $4 \mathrm{~h}$. A $1: 1$ ratio of $0.1 \mathrm{~mm} \varphi$ and $0.3 \mathrm{~mm} \varphi$ zirconia balls were used as the milling media.

\subsection{Preparation of seed}

We prepared the seed (Seed-1) by treating $\left(\mathrm{Al}\left(\mathrm{NH}_{4}\right)\right.$ $\left.\left(\mathrm{SO}_{4}\right)_{2}\right)$ (HMR Co., Korea) at $1200^{\circ} \mathrm{C}$ for $1 \mathrm{~h}$, and milling the produced $\alpha-\mathrm{Al}_{2} \mathrm{O}_{3}$ powder in a mixed solution of anhydrous ethyl ethanol (99.9\%, Daejung Chemical Co., Korea), and nitric acid (60\%, Daejung Chemical Co., Korea). It is further sand-milled for $5 \mathrm{~h}$ with zirconia beads as the grinding media (Ceontec Co., Korea). A $1: 1$ ratio of $0.1 \mathrm{~mm} \varphi$ and 0.3 $\mathrm{mm} \boldsymbol{\varphi}$ zirconia balls were used as the milling media. We selected the fine portion of the Seed-2 by centrifugal classification at $5000 \mathrm{rpm}$ for $10 \mathrm{~min}$. The concentrations of seed were 5.0 wt.\% and 0.5 wt.\% before and after classification, respectively.

\subsection{Synthesis of $\alpha$-alumina}

In the case of boehmite precursor, we ultrasonicated boehmite in methanol for $5 \mathrm{~min}$, and agitated the mixture with 1,4-butanediol and $\alpha-\mathrm{Al}_{2} \mathrm{O}_{3}$ seeds. Table 1 summarizes the details of samples prepared for this study. The same procedure was used for the preparation of gibbsite precursor. The residual methanol and ethanol of low-boiling points were removed in a vacuum rotational condenser at $60^{\circ} \mathrm{C}$ for 30 min. The remaining sol in 1.4-butanediol solvent of highboiling point was heated in a $100 \mathrm{ml}$-autoclave up to $300^{\circ} \mathrm{C}$ at the rate of $100^{\circ} \mathrm{C}$, heat-treated for $12 \mathrm{~h}$, and cooled down to RT. The heat-treated sample was further washed with isopropanol solution and dried at $120^{\circ} \mathrm{C}$.

\subsection{Phase analysis and characterization of raw materials and synthesized powders}

We analyzed crystal structure of the synthesized powder by XRD (DMAX2500, Rigaku) at $400 \mathrm{kV}, 20 \mathrm{~mA}$, scan speed of $5 \% \mathrm{~min}$, and in the range of $2 \theta=10 \sim 75^{\circ}$. For evaluation of particle size and shape of raw materials and synthesized powders, we adopted TEM (Transmission Electron Microscopy, JEEM-2000, JEOL) and SEM (Scanning electron microscopy, SM300, Topcon). We determined their particle size distributions with PSA (Particle Size Analysis, La-950, Horiba) and ELS-Z (Otsuka electronics). PSA operates based on static laser light scattering (SLS), while ELS-Z on dynamic light scattering (DLS).

\section{Results and Discussion}

\subsection{Characteristies of seed}

Figure 1 shows the effect of $\alpha-\mathrm{Al}_{2} \mathrm{O}_{3}$ seed on morphology and size of $\alpha-\mathrm{Al}_{2} \mathrm{O}_{3}$. Fig. 1(a) is TEM image of dispersed seeds presenting rather nonuniform sizes of seeds less than $100 \mathrm{~nm}$. Fig. 1(b) is the treated $\alpha-\mathrm{Al}_{2} \mathrm{O}_{3}$ seeds prepared initially at the high temperature, showing an average particle diameter of $2.33 \mu \mathrm{m}$. Note that the seed consists of primary particles of about $100 \mathrm{~nm}$ and agglomerated particles of 10 $\mu \mathrm{m}$ before milling. We confirmed that the average particle size of Seed-1 reduced to about $90 \mathrm{~nm}$ after milling. Seed-2 after removing its coarser portion of particles has an average particle diameter of $70 \mathrm{~nm}$.

Assuming a spherical shape of seeds, the measured average particle size by PSA is considered as the actual diameter. This will make calculations of seed contents in numbers per volume possible.

Figure 2 displays shape and size of precursors. Fig. 2(a) is SEM image of gibbsite precursor showing an average particle size of about $800 \mathrm{~nm}$. Fig. 2(b) is TEM image of boehmite precursor showing primary particles of about $20 \mathrm{~nm}$ that are interconnected with each other and dispersed as agglomerates. Fig. 2(c) shows PSA result of gibbsite precursor measured by SLS method. Its average particle sizes were $1.92 \mu \mathrm{m}$ and $95 \mathrm{~nm}$ before and after milling, respectively. Fig. 2(d) is a result obtained by DLS method, confirming average particle diameter of $80 \mathrm{~nm}$ for boehmite.

Table 1. Samples Prepared for the Study

\begin{tabular}{|c|c|c|c|c|c|c|}
\hline No & Precursor type & Precursor (g) & Solvent (mL) & seed type & $\begin{array}{l}\text { seed content } \\
\text { (particles/mL) }\end{array}$ & Reacion time (h) \\
\hline 1 & Boehmite & 2 & 45 & - & - & 36 \\
\hline 2 & Boehmite & 2 & 50 & Seed-1 & $5.3 \times 10^{9}$ & 12 \\
\hline 3 & Boehmite & 2 & 50 & Seed-1 & $1.4 \times 10^{11}$ & 12 \\
\hline 4 & Gibbsite milling & 2 & 45 & - & - & 36 \\
\hline 5 & Gibbiste milling & 2 & 50 & Seed-2 & $1.4 \times 10^{11}$ & 12 \\
\hline 6 & Boehmite & 2 & 50 & Seed-2 & $1.4 \times 10^{11}$ & 12 \\
\hline
\end{tabular}



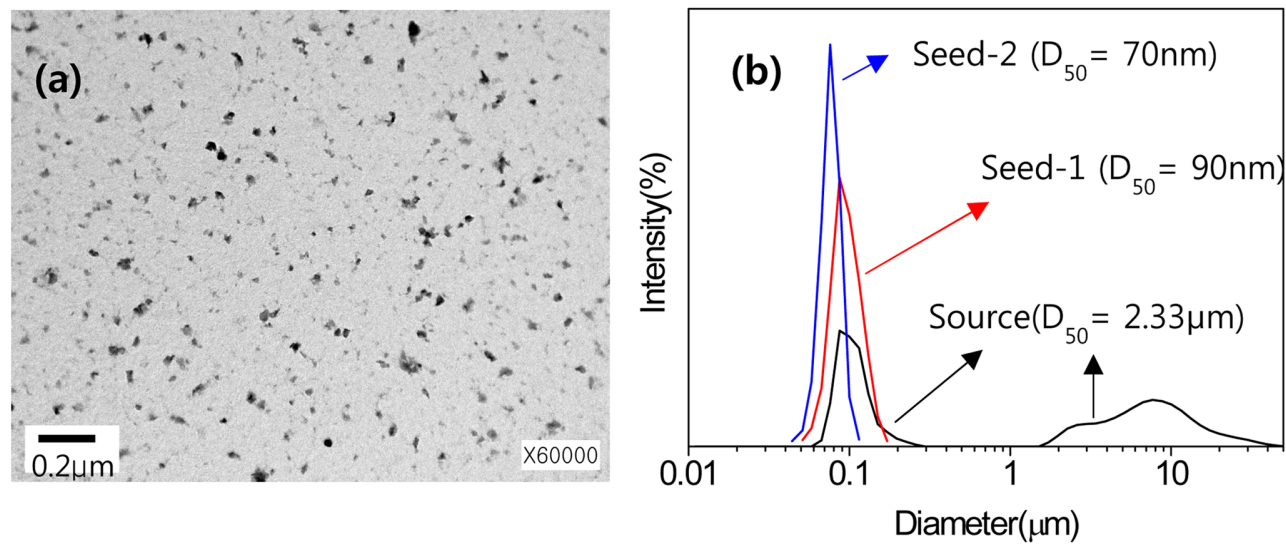

Fig. 1. (a) TEM image of $\alpha-\mathrm{Al}_{2} \mathrm{O}_{3}$ seeds (Seed-1), (b) PSA of $\alpha-\mathrm{Al}_{2} \mathrm{O}_{3}$ seed source and seeds prepared by milling and centrifuge.
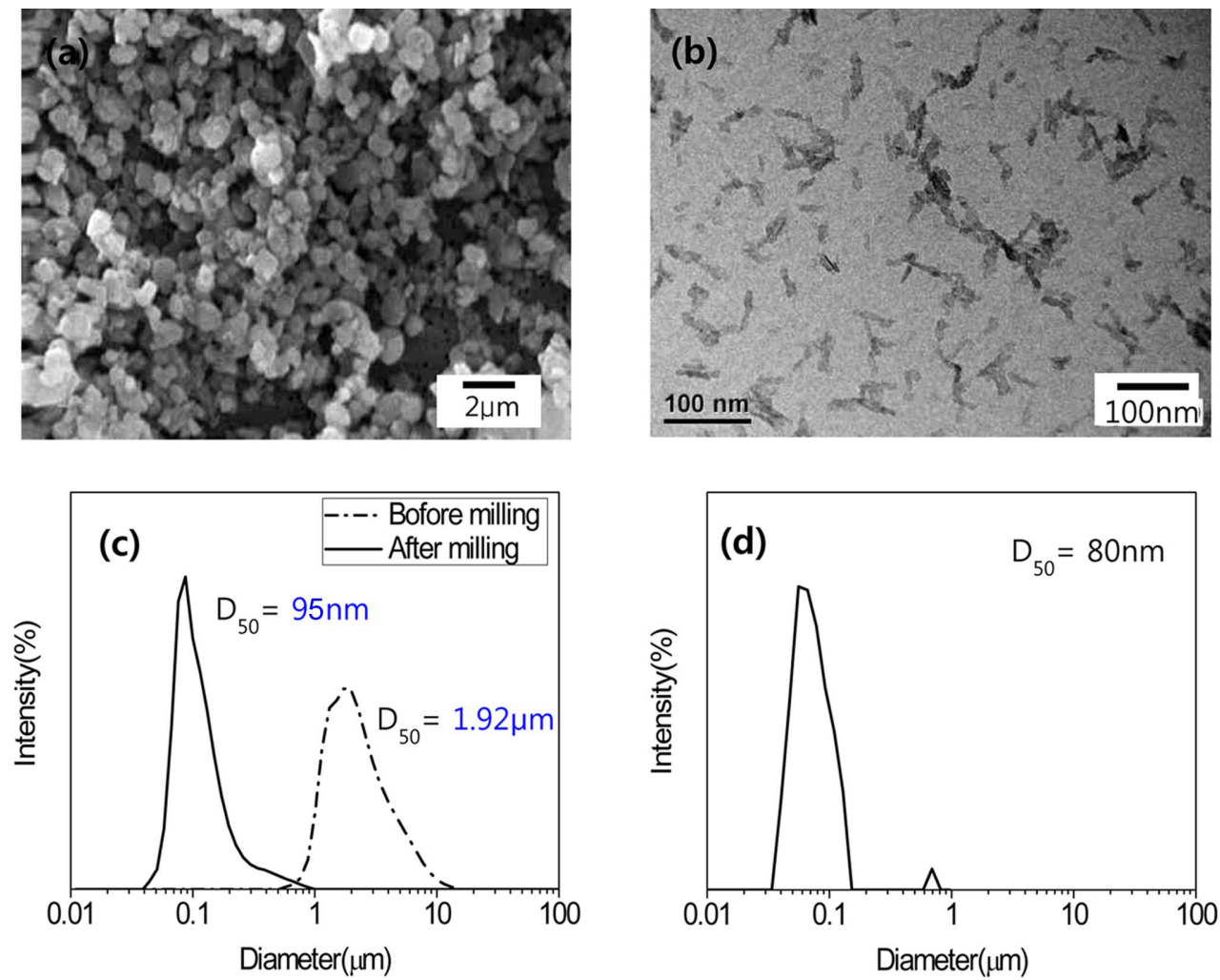

Fig. 2. (a) SEM image of gibbsite (b) TEM image of boehmite, (c) PSA of gibbsite by SLS method, (d) PSA of boehmite by DLS method.

\subsection{Properties of synthesized powders}

\subsubsection{Effect of seed content}

Figure 3 shows XRD patterns for the synthesized alumina in terms of precursor source and seed contents. The $2 \theta$ of 25.57, 35.14, 37.76, 43.33, 46.16, 52.53, 57.47, 61.27, 66.49, and 68.18 correspond to crystal planes of (012), (104), (110), (113), (202), (024), (116), (018), (214), and (300). We confirmed that they all match with those of the $\alpha-\mathrm{Al}_{2} \mathrm{O}_{3}$ (JCPDS NO. 42-1468). Fig. 3 (a) is the pattern of 36 -hr synthesized powder from boehmite precursor without seed. Intensity from $d(104)$ plane is relatively stronger than that from d(113) plane, suggesting the synthesized alumina could be in plate shape. Fig. 3(b) and (c) shows XRD patterns of synthesized powders with different seed contents. Intensity from $d(113)$ plane now becomes stronger than that from $\mathrm{d}(104)$ plane, regardless of seed contents. We assumed that the difference in relative peak intensity attributes to changes in particle morphology.

Figure 4 shows SEM images of synthesized powders with and without seed and different seed contents. Fig. 4(a) reveals plate-like $\mathrm{a}-\mathrm{Al}_{2} \mathrm{O}_{3}$ of $400 \mathrm{~nm}$ in diameter, produced by synthesis for $36 \mathrm{~h}$ without seed. Fig. 4(b) and (c) show 


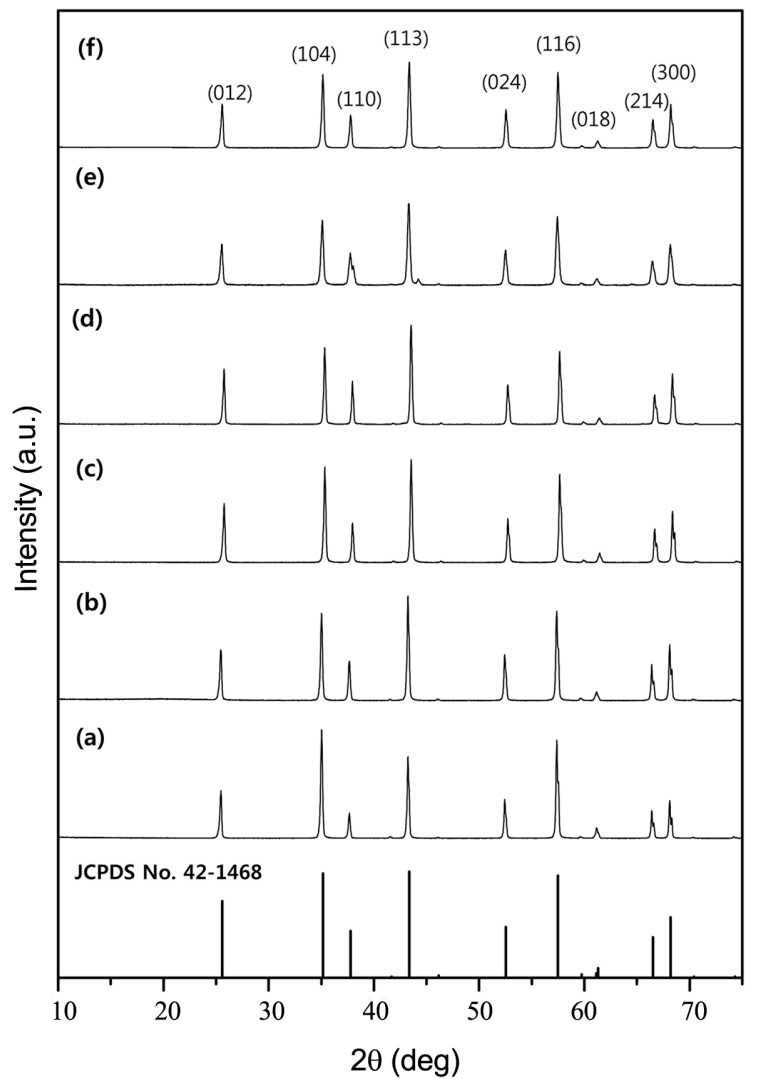

Fig. 3. XRD of as-synthesized powder as a function of concentration of seeds and of precursor type (a) sample 1, (b) sample 2, (c) sample 3, (d) sample 4, (e) sample 5 , and (f) sample 6. decreasing particle size of synthesized $\alpha-\mathrm{Al}_{2} \mathrm{O}_{3}$ with increasing amount of seed addition; Sample 2 of about $250 \mathrm{~nm}$ and Sample 3 of about $200 \mathrm{~nm}$, respectively. Sample 2 in Fig. 4(b) shows particles of rounded polygonal of $250 \mathrm{~nm}$, while Sample 3 in Fig. 4(c) particles of smaller and round of 200 $\mathrm{nm}$, respectively. This change in particle morphology is assumed to be responsible for the observed change in XRD pattern; seeding made the intensity of $d(113)$ stronger than that of $\mathrm{d}(104)$. We propose that increase in the number of seeds promotes nucleation around seeds, leading to growth of numerous alumina particles in a smaller dimension.

\subsubsection{Effect of precursor}

Figure 5 shows SEM images of three samples of as-synthesized $\alpha-\mathrm{Al}_{2} \mathrm{O}_{3}$. Fig. 5 (a) is as-synthesized $\alpha-\mathrm{Al}_{2} \mathrm{O}_{3}$ from gibbsite precursor without seed (Sample 4), that resulted in about $1 \mu \mathrm{m}$-sized hexagonal plates. Without seeding, we observed synthesized $\alpha-\mathrm{Al}_{2} \mathrm{O}_{3}$ (sample 4) in relatively bigger and thicker shape than that of the case of boehmite precursor (Sample 1).

Figure 5(b) is as-synthesized $a-\mathrm{Al}_{2} \mathrm{O}_{3}$ with seeds from gibbsite precursor (Sample 5), that resulted in rounded polygons of less than about $200 \mathrm{~nm}$. We confirmed that the seeding effectively reduced the particle size about five times compared to the unseeded one of $1 \mu \mathrm{m}$ (Fig. 5(a)).

Figure 5(c) is as-synthesized $a-\mathrm{Al}_{2} \mathrm{O}_{3}$ with seeds from boehmite precursor (Sample 6), that resulted in round polygons of less than about $200 \mathrm{~nm}$. It seems that Seed-2 produces synthesized $\alpha-\mathrm{Al}_{2} \mathrm{O}_{3}$ in more uniform size compared to Seed-1 case. We also confirmed that the addition of seeds
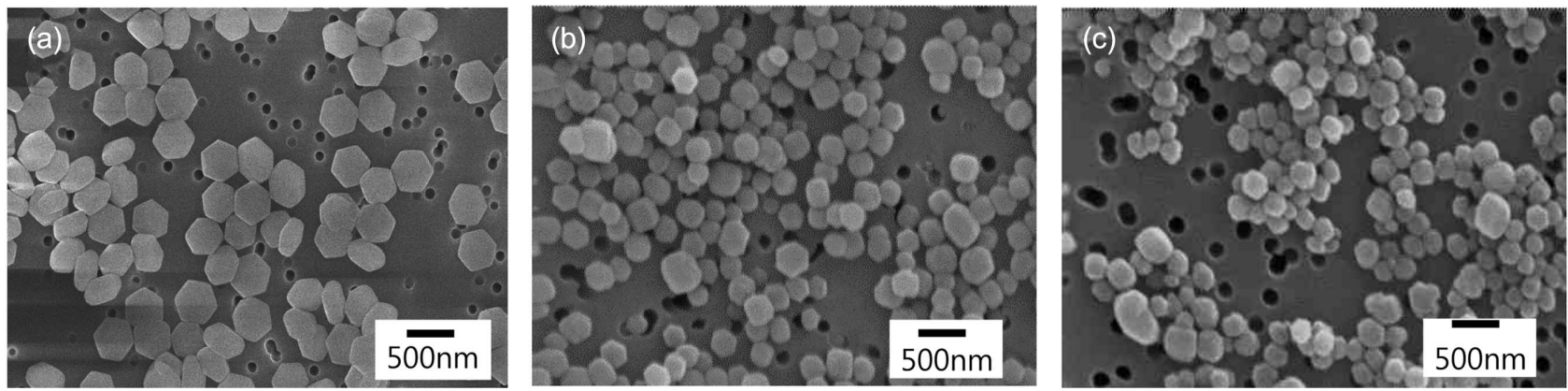

Fig. 4. SEM images of $\mathrm{a}-\mathrm{Al}_{2} \mathrm{O}_{3}$ as a function of seed concentration (Seed-1) (a) sample 1, (b) sample 2, and (c) sample 3 .
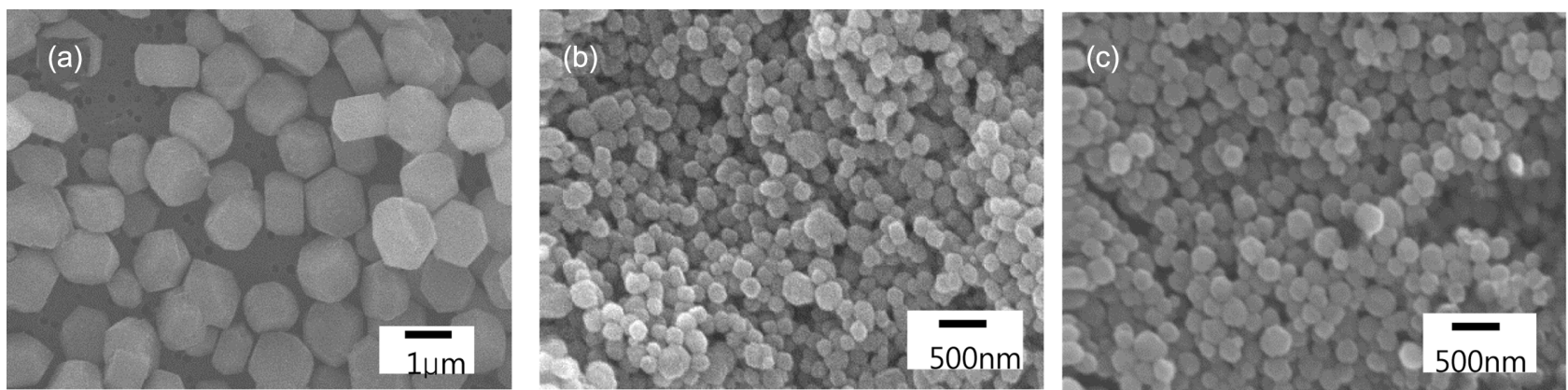

Fig. 5. SEM images of (a) as-synthesized $\alpha-\mathrm{Al}_{2} \mathrm{O}_{3}$ from gibbsite precursor without seed (Sample 4), (b) as-synthesized $\alpha-\mathrm{Al}_{2} \mathrm{O}_{3}$ from gibbsite precursor with seed-2 (Sample 5) and (c) as-synthesized $\alpha-\mathrm{Al}_{2} \mathrm{O}_{3}$ from boehmite precursor with seed-2 (Sample 6). 

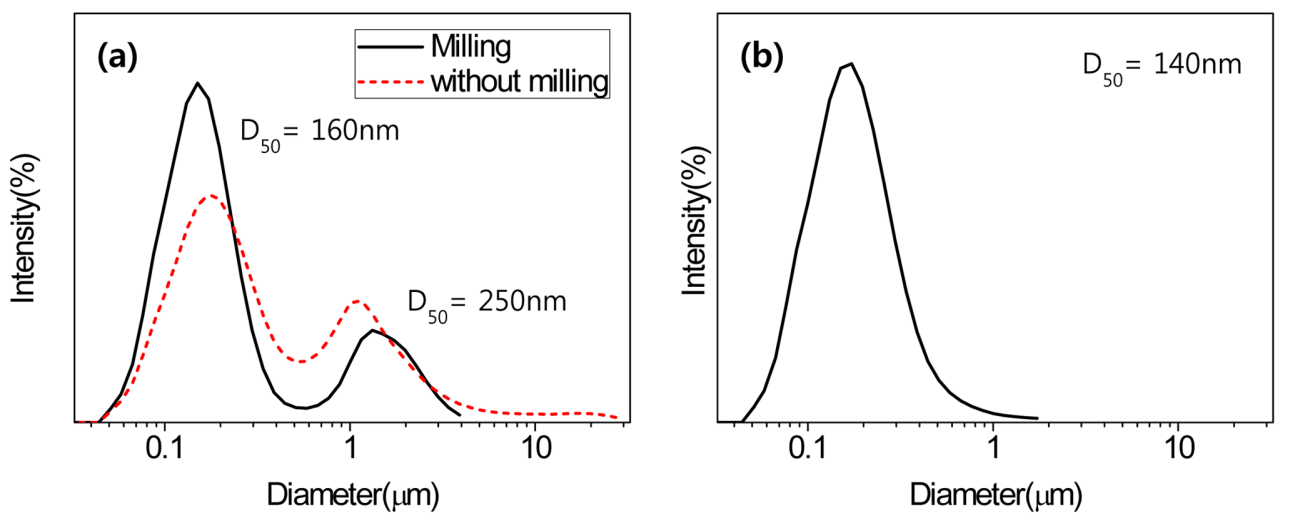

Fig. 6. PSA of as-synthesized $\alpha-\mathrm{Al}_{2} \mathrm{O}_{3}$ according to the precursor type (a) sample 5 (with and without milling), (b) sample 6.

into boehmite precursor reduced the size of particle half by decreasing from $400 \mathrm{~nm}$ (Fig. 4(a)) to $200 \mathrm{~nm}$ (Fig. 4(c)). Fig. 5(b) and (c) indicates that both gibbsite and boehmite precursor produced $\alpha-\mathrm{Al}_{2} \mathrm{O}_{3}$ of $140 \sim 160 \mathrm{~nm}$ under the same seeding condition.

Figure 6 shows particle size distribution of synthesized $\alpha$ $\mathrm{Al}_{2} \mathrm{O}_{3}$ from different precursor with the same amount of seed addition. Fig. 6(a) indicates that average particle diameter of synthesized $\alpha-\mathrm{Al}_{2} \mathrm{O}_{3}$ from milled gibbsite precursor is 160 $\mathrm{nm}$, while that of unmilled one is $250 \mathrm{~nm}$. Synthesized $\alpha$ $\mathrm{Al}_{2} \mathrm{O}_{3}$ powders from gibbsite precursor before and after milling show similar primary particle size. Agglomeration, however, was reduced with precursor milling, that leads to decrease in mean particle diameter.

Figure 6(b) is synthesized $\alpha-\mathrm{Al}_{2} \mathrm{O}_{3}$ from boehmite precursor showing average particle diameter of $140 \mathrm{~nm}$. We confirmed that Seed-1 resulted in $270 \mathrm{~nm}$ of $\alpha-\mathrm{Al}_{2} \mathrm{O}_{3}$ (sample 3), while Seed-2 in $140 \mathrm{~nm}$, respectively. It is also observed that classified fine seeds produced relatively uniform formation for $\alpha-\mathrm{Al}_{2} \mathrm{O}_{3}$ particles.

We confirmed that, according to SEM results, our synthesized alumina (Sample 4 and Sample 5) from gibbsite have similar morphology to previously reported alumina from gibbsite precursor. ${ }^{13)}$ However, the study did not specify the dispersion detail of raw material and the particle size distribution of synthesized $\alpha-\mathrm{Al}_{2} \mathrm{O}_{3}$. Depending on the source and size of precursor, its dissolution rate could be different, and that might lead to different nucleation, the growth rate for particles, and their final morphologies.

Boehmite is finer compared to the primary particles of gibbsite (Fig. 2(b)), and thus dissolves relatively faster in 1,4-butanediol solvent. This leads to formation of smaller $\alpha$ alumina compared to the case of gibbsite precursor. This implies that, even with seeds, boehmite precursor itself can dissolve and nucleate fast enough to conceal the seeding effect. We, therefore, concluded that using boehmite is preferred one since it simplifies the overall process. Note that it only needs dispersion with no milling to have mono-dispersed $\alpha-\mathrm{Al}_{2} \mathrm{O}_{3}$ seeds to be used for alumina synthesis.

\section{Conclusions}

We performed a series of experiments for synthesis of $\alpha$ $\mathrm{Al}_{2} \mathrm{O}_{3}$ from boehmite and gibbsite precursors with and without $\alpha-\mathrm{Al}_{2} \mathrm{O}_{3}$ seeds via solvothermal process at $300^{\circ} \mathrm{C}$. Boehmite precursor without seed resulted in synthesis of $400 \mathrm{~nm}$ plate-like $\alpha-\mathrm{Al}_{2} \mathrm{O}_{3}$, while gibbsite precursor in synthesis of 1 $\mu \mathrm{m}$ plate-like $\alpha-\mathrm{Al}_{2} \mathrm{O}_{3}$ in a thicker dimension. We confirmed that increase in the number of seeds in a given volume enhances nucleation rate, faster growth of alumina particles, and hence smaller synthesized particles. Furthermore, gibbsite seeds demonstrated a better effect than boehmite. However, under the same condition of seed addition, boehmite precursor resulted in a mono-modal distribution of particle size, while gibbsite precursor in bi-modal one. We also concluded that boehmite precursor dissolves in 1,4-butanediol solvent relatively fast, and nucleation is enhanced by itself, concealing the actual effect of seeding. Gibbsite precursor, however, needed a ball milling process to minimize agglomeration for smaller overall average particle diameter, although the primary particle size remained unchanged.

\section{Acknowledgments}

Authors gratefully acknowledge the support for this study by Energy Technology Development Project (20131020000130, Development of Electrical Insulation Nanohybrid Materials for Motor(Rectangular) Coil).

\section{REFERENCES}

1. O. Mekasuwandumrong, V. Pavarajarn, M. Inoue, and P. Praserthdam, "Preparation and Phase Transformation Behavior of X-Alumina via Solvothermal Synthesis," Mater. Chem. physics, 100 [2-3] 445-50 (2006).

2. K. Inoue, M. Hama, Y. Kobayashi, Y. Yasuda, and T. Morita, "Low Temperature Synthesis of a-Alumina with a Seeding Technique," ISRN Ceramics, 2013 1-5 (2013).

3. X. Shen, X. Nie, H. Hu, and J. Tjong, "Effects of Coating Thickness on Thermal Conductivities of Alumina Coatings 
and Alumina/aluminum Hybrid Materials Prepared Using Plasma Electrolytic Oxidation," Surf. Coat. Technol., 207 [25] 96-101 (2012).

4. Z. Q. Yu, C. X. Wang, X. T. Gu, and C. Li, "Photoluminescent Properties of Boehmite Whisker Prepared by Sol-gel process," J. luminescence, 106 [2] 153-57 (2004).

5. M. T. Swihart, "Vapor-Phase Synthesis of Nanoparticles," Curr. Opin. Colloid Interface Sci., 8 [1] 127-33 (2003).

6. R. J. Yang, F. S. Yen, S. M. Lin, and C. C. Chen, "MicroStructure-Controlled Effects on Temperature Reduction of a- $\mathrm{Al}_{2} \mathrm{O}_{3}$ Crystallite Formation," J. Cryst. Growth, 299 [2] 429-35 (2007).

7. P. C. Yu, R. J. Yang, Y. T. Chang, and F. S. Yen, "Fabrication of Nano-Scaled $\alpha-\mathrm{Al}_{2} \mathrm{O}_{3}$ Crystallites Through Heterogeneous Precipitation of Boehmite in a Well-Dispersed $\theta$ $\mathrm{Al}_{2} \mathrm{O}_{3}$-Suspension," J. Am. Ceram. Soc., 90 [8] 2340-46 (2007).

8. R. Uyeda, "Studies of Ultrafine Particles in Japan: Crystallography. Methods of Preparation and Technological Applications," Prog. Mater. Sci., 35 [1] 1-96 (1991).

9. L. Qu, C. He, Y. Yang, Y. He, and Z. Liu, "Hydrothermal Synthesis of Alumina Nanotubes Templated by Anionic Surfactant," Mater. Lett., 59 [29-30] 4034-37 (2005).

10. N. S. Bell and J. H. Adair, "Adsorbate Effects on Glycothermally Produced a-Alumina Particle Morphology," J. Cryst. Growth, 203 [1-2] 213-26 (1999).

11. M. Inoue, H. Tanino, Y. Kondo, and T. Inui, "Formation of Microcrystalline a-Alumina by Glycothermal Treatment of
Gibbsite," J. Am. Ceram. Soc., 72 [2] 352-53 (1989).

12. A. Kaiser, D. Sporn, and H. Bertagnolli, "Phase Transformations and Control of Habit in Lyothermal Synthesis of a$\mathrm{Al}_{2} \mathrm{O}_{3}$," J. Euro. Ceram. Soc., 14 [1] 77-83 (1994).

13. N. S. Bell, S. B. Cho, and J. H. Adair, "Size Control of aAlumina Particles Synthesized in 1,4-Butanediol Solution by a-Alumina and a-Hematite Seeding," J. Am. Ceram. Soc., 81 [6] 1411-20 (1998).

14. G. F. Fu, W. Jing, and K. Jian, "Influence of $\mathrm{AlF}_{3}$ and Hydrothermal Conditions on Morphologies of $\mathrm{a}-\mathrm{Al}_{2} \mathrm{O}_{3}$," Transa. Nonferrous Met. Soc. China, 18 [3] 743-48 (2008).

15. H. S. Kim and M. S. Kang, "Rapid Crystal Phase Transformation into Hexagonally Shaped a-Alumina Using AlF3 Seeds," J. Sol-gel Sci. Technol., 68 [1] 110-20 (2013).

16. R. A. Shelleman, G. L. Messing, and M. Kumagai, "Alpha Alumina Transformation in Seeded Boehmite Gels," $J$. Non-Cryst. Solids, 82 [1-3] 277-85 (1986).

17. M. Kumagai and G. L. Messing, "Enhanced Densification of Boehmite Sol-Gels by a-Alumina Seeding," J. Am. Ceram. Soc., 67 [11] c230-31 (1984).

18. S. Kwon and G. L. Messing, "Sintering of Mixtures of Seeded Boehmite and Ultrafine a-Alumina," J. Am. Ceram. Soc., 83 [1] 82-8 (2000).

19. H. Y. Jo, S. H. Lee, D. S. Kim, Y. K. Lee, and H. M. Lim, "Synthesis of Alpha- $\mathrm{Al}_{2} \mathrm{O}_{3}$ from Boehmite Precursors through a Solvothermal Synthesis," Mater. Express, submitted. 